\title{
Pulmonary Nodules
}

\section{A Small Problem for Many, Severe Distress for Some, and How to Communicate About It}

\author{
Christopher G. Slatore, MD; and Renda Soylemez Wiener, MD, MPH
}

\begin{abstract}
Every year, millions of patients are diagnosed with pulmonary nodules, and as increasing numbers of people undergo lung cancer screening, even more patients will be found to have a nodule. The vast majority of patients cannot benefit from the detection of a pulmonary nodule because most are benign. Accordingly, it is important to develop strategies to minimize harm, in particular the distress of a "near-cancer" diagnosis. In other settings, communication strategies are critical mediators of patient-centered outcomes for those with cancer and those at-risk of cancer. We conducted multiple studies to characterize the experience of patients with the diagnosis and evaluation of incidental pulmonary nodules, measure patient-centered outcomes for patients with pulmonary nodules, and determine the association of patient-clinician communication practices with those outcomes. We learned that a substantial proportion of patients experience distress and inadequate communication about pulmonary nodules and their evaluation, and yet many clinicians are unaware of the degree to which some patients are affected by the finding of a pulmonary nodule. The present review provides a comprehensive summary of our results and offers suggestions for how clinicians can best provide high-quality communication for their patients.

CHEST 2018; 153(4):1004-1015
\end{abstract}

KEY WORDS: health communication; lung cancer; pulmonary nodule

Every year, millions of patients have an incidental pulmonary nodule identified on chest imaging studies, ${ }^{1,2}$ and the number of nodules will only increase with implementation of lung cancer screening. ${ }^{3}$ Although the vast majority of nodules are ultimately determined to be false-positive findings for lung cancer, ${ }^{4,5}$ it is challenging to determine if a small nodule is malignant when first identified. Expert guidelines recommend active surveillance, often managed by nonspecialists, to detect the few cases of lung cancer at an early stage when cure rates are substantially better. ${ }^{6,7}$ Although few stand to benefit, all patients are at risk of iatrogenic harm from detection
ABBREVIATIONS: CPS = Control Preferences Scale; $\mathrm{PCP}=$ primary care provider; VA = Department of Veterans Affairs

AFFILIATIONS: From the Center to Improve Veteran Involvement in Care (Dr Slatore) and Section of Pulmonary \& Critical Care Medicine (Dr Slatore), VA Portland Health Care System, Portland, OR; Division of Pulmonary \& Critical Care Medicine (Dr Slatore), Department of Medicine, Oregon Health \& Science University, Portland, OR; Center for Healthcare Organization \& Implementation Research (Dr Wiener), Edith Nourse Rogers Memorial VA Hospital, Bedford, MA; and The Pulmonary Center (Dr Wiener), Boston University School of Medicine, Boston, MA.

FUNDING/SUPPORT: This study was sponsored by a Department of Veterans Affairs Health Services Research and Development Service
Career Development Award [Grant CDA 09-025 \& CDP 11-227] to Dr Slatore and a career development award from the National Cancer Institute [Grant K07 CA138772] to Dr Wiener. It was also supported by resources from the VA Portland Health Care System and the Edith Nourse Rogers Memorial VA Hospital.

CORRESPONDENCE TO: Christopher G. Slatore, MD, 3710 SW US Veterans Hospital Rd, R\&D 66, Portland, OR 97239; e-mail: christopher.slatore@va.gov

Published by Elsevier Inc. under license from the American College of Chest Physicians.

DoI: https://doi.org/10.1016/j.chest.2017.10.013 
and evaluation of a pulmonary nodule. Accordingly, it is important to mitigate the severity and frequency of these harms. Harris et $\mathrm{al}^{8}$ proposed a taxonomy of harms that result from a "near-cancer" diagnosis after a nodule is detected through lung cancer screening. This taxonomy applies equally to incidental nodule detection and includes physical harms, psychological harms, financial strain, and opportunity costs.

We believe it is critical to evaluate patient-centered outcomes following nodule detection for several reasons. First, incidental nodule detection is already common, and with the advent of screening, clinicians risk becoming inundated with patients with pulmonary nodules that require evaluation. Second, we wanted to evaluate patients with a low risk of lung cancer because this group represents the vast majority of those with a nodule. Many studies have focused on the impact of cancer detection on patients but fewer on the impact of a "near-cancer" diagnosis.

Third, almost everyone with a nodule has a risk of suffering psychological harm. When we started our research studies, however, there were no data on the likelihood or magnitude of those harms. As an example from a related setting, we knew that patients with falsepositive mammograms frequently experience distress. ${ }^{9,10}$ In the context of false-positive mammograms, distress is often short-lived and resolved when results of a breast biopsy are negative. However, most patients with pulmonary nodules undergo radiographic surveillance rather than biopsy, leaving them in a state of uncertainty for months or years about whether they have cancer. We each had clinical experiences talking with patients who experienced profound and prolonged distress after their pulmonary nodule was detected. Thus, we wanted to study how commonly distress occurred and how severe it was for patients with nodules. We focused on psychological harm because most patients with small nodules undergo radiologic surveillance and are less likely to suffer physical harm or financial strain. Furthermore, for the subset of patients who do undergo invasive procedures, physical harms may be hard to change, as they result from mostly fixed patient and imaging characteristics (eg, comorbid illness, size and location of nodule).

Finally, and most importantly, we wanted to understand if there were mechanisms to influence distress and other patient-centered outcomes. We hypothesized that communication strategies would be a likely, if not the only, mechanism to influence distress. We also reasoned that understanding this communication process would provide valuable insights into how clinicians made recommendations about nodule surveillance and what impact these processes had on patients' adherence to recommendations.

\section{The Studies Begin}

Simultaneously but independently, we applied for and were awarded career development awards from the National Cancer Institute (Dr Wiener) and the Department of Veterans Affairs (VA) (Dr Slatore). The proposed studies were a mix of qualitative and quantitative analyses of patients with nodules along with the clinicians who care for these patients. The main differences in the designs were that Dr Wiener included patients from several health-care systems in the northeastern United States and focused on large-scale cross-sectional analyses. Dr Slatore performed a smaller study but with longitudinal evaluations and only included patients from one VA facility in the northwestern United States. The goal of the studies was to evaluate the association of communication practices, as reported by both patients and clinicians, with patientcentered outcomes. The primary outcome was distress, but adherence, knowledge, and satisfaction were also studied. When available, validated instruments were used to measure these outcomes (Table 1).

We were guided by theoretical models of patientcentered communication to help measure and analyze communication strategies. These models emphasize the separate practices that comprise communication, which can each be measured and replicated. Most models agree on four core domains (Fig 1): (1) information exchange, in which a clinician informs a patient about the risks and benefits of diagnostic and treatment options; (2) understanding the patient as a person and his or her preferences and values, which can be divided into tasks such as fostering healing relationships, responding to emotions, and managing uncertainty $^{11}$; (3) shared decision-making, which combines adequate information exchange with considering patients' values and preferences to make an informed decision that is shared between the patient and clinician; and (4) establishing a therapeutic alliance so that the patient and clinician are "on the same page." Some patient-centered communication models also emphasize the "clinician as person" domain, which incorporates the personal qualities of 
TABLE 1 ] Associations of Communication Domains With Patient-Centered Outcomes

\begin{tabular}{|c|c|c|}
\hline Measure/Exposure & Outcome & Direction (If Exposure Increasing) \\
\hline General quality of communication & $\begin{array}{l}\text { Distress } \\
\text { Perceived lung cancer risk } \\
\text { Adherence (patient) } \\
\text { Adherence (clinician) }\end{array}$ & $\begin{array}{l}\text { Decreased (baseline and longitudinal) } \\
\text { No association } \\
\text { Nmproved }^{21} \\
\text { No association } \\
\text { Ne }^{27}\end{array}$ \\
\hline \multicolumn{3}{|l|}{ Information exchange } \\
\hline Satisfied with information & $\begin{array}{l}\text { Distress } \\
\text { Perceived lung cancer risk }\end{array}$ & $\begin{array}{l}\text { No association }{ }^{21} \\
\text { No association }\end{array}$ \\
\hline Perceived lung cancer risk & $\begin{array}{l}\text { Distress } \\
\text { Adherence (patient) } \\
\text { Adherence (clinician) } \\
\text { Actual risk }\end{array}$ & $\begin{array}{l}\text { No association (in baseline and } \\
\text { multicenter) }^{21,19} \\
\text { No association }^{27} \\
\text { No association }^{27} \\
\text { No association }^{19}\end{array}$ \\
\hline $\begin{array}{l}\text { Inability to estimate risk } \\
\text { Mode (letter vs other); clinician role }\end{array}$ & $\begin{array}{l}\text { Distress } \\
\text { Distress }\end{array}$ & $\begin{array}{l}\text { No association } \\
\text { No association }^{21}\end{array}$ \\
\hline $\begin{array}{l}\text { Patient as person } \\
\text { Partnership with the clinician } \\
\text { Relationship with the clinician } \\
\text { Positive approach } \\
\text { Interest in participant's life }\end{array}$ & Distress & All decreased ${ }^{22}$ \\
\hline $\begin{array}{l}\text { Decision-making } \\
\text { Preferred role } \\
\text { Actual role }\end{array}$ & $\begin{array}{l}\text { Distress } \\
\text { Distress } \\
\text { Satisfaction with care } \\
\text { Quality of medical care } \\
\text { Perceived lung cancer risk } \\
\text { Nodule information satisfaction }\end{array}$ & $\begin{array}{l}\text { No association } \\
\text { No association } \\
\text { N2 } \\
\text { No association } \\
\text { N7 } \\
\text { No association }^{37} \\
\text { No association }^{37} \\
\text { No association }^{37}\end{array}$ \\
\hline $\begin{array}{l}\text { Concordant with actual decision and } \\
\text { preferred role in decision-making }\end{array}$ & $\begin{array}{l}\text { Distress } \\
\text { Satisfaction with care } \\
\text { Quality of medical care } \\
\text { Perceived lung cancer risk } \\
\text { Nodule information satisfaction }\end{array}$ & $\begin{array}{l}\text { No association }{ }^{22} \\
\text { Improved }^{37} \\
\text { Improved }^{37} \\
\text { Not associated }^{37} \\
\text { Not associated }^{37}\end{array}$ \\
\hline Other notable associations & & \\
\hline $\begin{array}{l}\text { Objective risks of lung cancer (eg, } \\
\text { age, smoking status, nodule size, } \\
\text { Mayo calculated risk) }\end{array}$ & $\begin{array}{l}\text { Distress } \\
\text { Perceived risk of lung cancer }\end{array}$ & $\begin{array}{l}\text { No association } \\
21, a \\
\text { Increased }^{22}\end{array}$ \\
\hline Posttraumatic stress disorder & $\begin{array}{l}\text { Distress } \\
\text { Perceived risk of lung cancer }\end{array}$ & $\begin{array}{l}\text { Increased }^{21} \\
\text { Decreased }^{21}\end{array}$ \\
\hline $\begin{array}{l}\text { Depression } \\
\text { Distress }\end{array}$ & $\begin{array}{l}\text { Distress } \\
\text { Adherence (patient) } \\
\text { Adherence (clinician) }\end{array}$ & $\begin{array}{l}\text { Increased }^{19,21} \\
\text { Decreased }^{27} \\
\text { No association } \\
27\end{array}$ \\
\hline
\end{tabular}

aExcept smoking status associated with increased distress in Freiman et al. ${ }^{19}$

the clinician. This domain was used to guide qualitative interviews of clinicians about their practices and communication surrounding nodule evaluation. As recommended by the National Institutes of Health and the American Thoracic Society, ${ }^{12-14}$ we sought to understand the longitudinal association between 


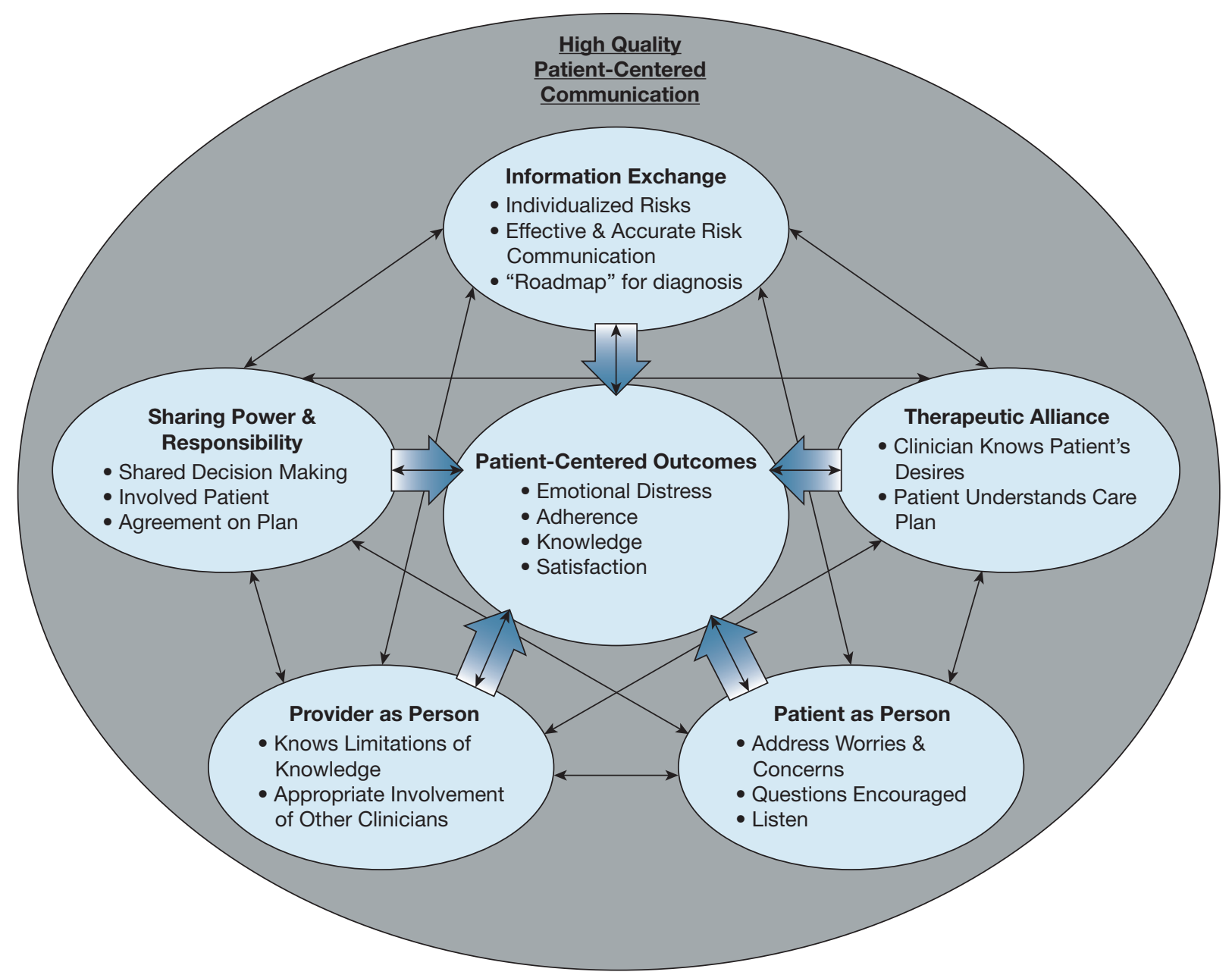

Figure 1 - The figure shows a theoretical model of the possible relationships between different domains of patient-centered care and patient-centered outcomes among patients with incidentally detected pulmonary nodules.

communication and distress to better assess the causal nature of this relationship.

Based on the patient-centered communication model, ${ }^{15,16}$ our primary hypothesis was that high-quality communication would be associated with less distress. We further hypothesized that high-quality communication in the information exchange domain, measured by a patient's self-perceived risk of lung cancer, was the most important mediator of distress for patients with nodules. Our experience was that many patients overestimated their risk of lung cancer, and these patients seemed to be more distressed than those who recognized their cancer risk to be low. Finally, we hypothesized that shared decision-making would be strongly associated with knowledge about the nodule because a core tenet of shared decision-making is providing the necessary medical information about risks, benefits, and options.

\section{What We Found}

Overall, most of our results from both cohorts studied were similar and complemented each other, with a few differences that are highlighted here.

As we suspected, many participants were distressed after they were diagnosed with an incidental nodule. Our qualitative studies showed that many seemed not at all or only mildly distressed, but some reported severe levels of distress, particularly in the period immediately following nodule detection. For example, one participant reported how she "bawled through Christmas"17 while another reported feeling like he had received a "death sentence" 18 after finding out about the nodule. Many of our participants reported that they immediately assumed they had cancer (Table 2). ${ }^{17}$ Our quantitative results confirmed these findings. For example, in Dr Wiener's cross-sectional study ${ }^{19}$ among patients with an average nodule size of $7 \mathrm{~mm}$ (median risk of lung cancer 
TABLE 2 ] Representative Quotes

\begin{tabular}{|c|c|c|}
\hline Outcome & Patient Perspective & Physician Perspective \\
\hline Distress & $\begin{array}{l}\text { My kidney doctor calls me up and says, "Oh by the } \\
\text { way, we found a tumor on your lungs." They } \\
\text { didn't even know what it was, but it was just the } \\
\text { way [he] came out and said it. I was } \\
\text { devastated.... I bawled through Christmas. }{ }^{17} \\
\text { Basically I was devastated. I thought I had cancer. I } \\
\text { called my son and my daughter-in-law and told } \\
\text { them I needed to talk to them. You know, in } \\
\text { Oregon they got assisted suicide, and there is no } \\
\text { way am I gonna be like my mother. I do not want } \\
\text { to get to that point. But I would go the route of } \\
\text { assisted suicide. }{ }^{18} \\
\text { Oh, I wouldn't have minded a biopsy right away. } \\
\text { Because then you know. With the family history I } \\
\text { think like, why wait a whole year? Because that's } \\
\text { a whole year of me thinking about it. And that's a } \\
\text { year I got to worry about it. I'm an insomniac, I } \\
\text { already got enough sleepless nights. }{ }^{38} \\
\text { Actually, I don't think I even asked [the PCP] about } \\
\text { anything. I was more concerned with this } \\
\text { pressure in my stomach there and that kept } \\
\text { pushing against my lungs and making it a bit } \\
\text { difficult to breathe and trying to figure out what } \\
\text { that was. Because that I could feel. And that's } \\
\text { what I wanted taken care of. And something that } \\
\text { wasn't bothering me [the nodule]-forget it-I } \\
\text { couldn't care less. }{ }^{18} \\
\text { I'm not living thinking that I'm going to get cancer } \\
\text { from this... Yes, there's a possibility that I could. } \\
\text { But at that point in time I will deal with it. I do not } \\
\text { worry about something before it happens. }{ }^{26}\end{array}$ & $\begin{array}{l}\text {...I feel like you must bring [cancer] up because } \\
\text { that's something that if they're not thinking it, } \\
\text { then maybe I didn't need to bring it up. But if } \\
\text { they're thinking it and I don't bring it up then } \\
\text { that's what's going to worry them when they go } \\
\text { home. So I try to be very up-front with what we're } \\
\text { evaluating. } \\
\text { Some people are super worried... They give you a } \\
\text { story about their brother who had cancer and had a } \\
\text { very bad experience because the doctors didn't get } \\
\text { it in time and now they have metastatic cancer. } \\
\text { You're like, 'all right, I guess we'll do the three } \\
\text { month [CT scan].' ... Would I be convinced to } \\
\text { biopsy something I didn't think was [cancer]? } \\
\text { Maybe, but certainly not go beyond anything more } \\
\text { invasive than that. }{ }^{33}\end{array}$ \\
\hline $\begin{array}{l}\text { Knowledge } \\
\text { about } \\
\text { nodule } \\
\text { (or lack of } \\
\text { it) }\end{array}$ & $\begin{array}{l}\text { Yeah, [the PCP] explained what calcification meant, } \\
\text { that that was an indication of how you can get } \\
\text { nodules, why it's likely that what I have is from } \\
\text { other things that occurred earlier. } \\
\text { I5 } \\
\text { It's kind of-hearing 'nodule' it's like in that movie } \\
\text { Armageddon when they talked about 'anomalies.' } \\
\text { Stop with this 'anomaly' horse-shit. Tell me what } \\
\text { it really is. Stop with the 'nodule' thing. What's } \\
\text { really going on? It doesn't mean anything. I don't } \\
\text { even know what a 'nodule' is. A spot? A pocket of } \\
\text { weirdness? } \\
\text { It's a scary roller coaster ride... I've never gotten } \\
\text { any definitive answers... And that's scary in itself, } \\
\text { not knowing. } \\
\text { There was really no explanation at all. Just, 'This is } \\
\text { it, this is what we've found, we want you back in } \\
6 \text { months.' And I was like, 'Well, what should I } \\
\text { expect? Should I expect to not be able to breathe } \\
\text { at all? Should I expect pain? Should I expect } \\
\text { changes in my physical self?' And no [answers] } \\
\text { ever came. }{ }^{17}\end{array}$ & $\begin{array}{l}\text { I don't [use the word 'cancer'] because I'm not that } \\
\text { worried-yet. But I'm not specifically trying to } \\
\text { avoid worrying the patient. I'm just giving them } \\
\text { the information. }{ }^{32} \\
\text { We usually don't mention lung cancer specifically; } \\
\text { we leave it a bit more nebulous. "There's a } \\
\text { non-specific abnormality. We don't know what it } \\
\text { means. But we do have some concern about it and } \\
\text { we're ordering further testing." } 33\end{array}$ \\
\hline $\begin{array}{c}\text { Patient as } \\
\text { person }\end{array}$ & $\begin{array}{l}\text { All I'm doing is being a patient, you know? No } \\
\text { doctors have been asking me my opinion. }{ }^{38} \\
\text { Yeah I didn't know what [the nodule] was so I didn't } \\
\text { concern myself. I went on vacation anyhow. I feel } \\
\text { okay. I feel fine. If it's something life-threatening } \\
\text { or something like that, I'm sure I would have been } \\
\text { notified. I trust [my hospital] implicitly. }{ }^{18} \\
\text { Would [doctors] want to go through that every } \\
3 \text { months?... Knowing what they're putting them } \\
\text { through?... They're looking at the medical part of } \\
\text { it and... not thinking of the consequences. }{ }^{17}\end{array}$ & $\begin{array}{l}\text { If you're with the person, you hear it in the tone of } \\
\text { what they're saying or in the body language. } \\
\text { You pretty much know your nervous Nellies. And you } \\
\text { know who's going to worry and you know whose } \\
\text { wife is going to worry. }\end{array}$ \\
\hline
\end{tabular}




\begin{tabular}{|c|c|c|}
\hline Outcome & Patient Perspective & Physician Perspective \\
\hline $\begin{array}{c}\text { Therapeutic } \\
\text { alliance }\end{array}$ & $\begin{array}{l}\text { [My doctor] said, "I think even given the risk of the } \\
\text { increased radiation, it's probably a good idea." I } \\
\text { trust her. We discuss everything. And so I feel } \\
\text { very comfortable with what I'm doing. }{ }^{17} \\
\text { I had confidence in him [PCP] and I figured if it was } \\
\text { something that he was really worried about he } \\
\text { would have done more about it. Even though it } \\
\text { made me feel kind of iffy about stuff, I figured that } \\
\text { he wasn't worried so I shouldn't be. }{ }^{18}\end{array}$ & $\begin{array}{l}\text { If [the patient] says, "whatever you think, doc," I } \\
\text { usually don't leave it at that... I'll tell them what } \\
\text { the stakes are and what the situation is, and I'll } \\
\text { say to them, "I can't really decide for you." I'll } \\
\text { specifically say, "Some people, as soon as you } \\
\text { mention that there is something in there that could } \\
\text { be a cancer, even if it is unlikely, they want it out } \\
\text { right away, and other people don't worry about } \\
\text { these things at all. What kind of a person are } \\
\text { you?"... I think by and large patients make very } \\
\text { appropriate decisions. And I think their adherence } \\
\text { to those decisions is enhanced when they have } \\
\text { participated." } 33\end{array}$ \\
\hline $\begin{array}{l}\text { Preferences } \\
\text { and } \\
\text { values }\end{array}$ & $\begin{array}{l}\text { I wouldn't want to get that information over the } \\
\text { phone. I would have wanted him to show me } \\
\text { pictures, explain what it was, what's going on. I'm } \\
\text { an 'information' kind of guy. }{ }^{18} \\
\text { I want to know the pros and cons of it before I make } \\
\text { any decision. You don't just go in and say I'm } \\
\text { gonna do it. } \\
\text { I would like to know. I don't-you know if I knew } \\
\text { more about them [the nodules] then I guess I } \\
\text { could make a plan but I don't know. }{ }^{18} \\
\text { I don't know enough about what I have to make an } \\
\text { informed decision on my own. }{ }^{38}\end{array}$ & $\begin{array}{l}\text { I'd say I pretty much tell them what their radiologist } \\
\text { recommends. I guess my patient population tends } \\
\text { to be one that says, "You're the doctor." They're } \\
\text { not a population that questions things a lot... They } \\
\text { tend to be pretty adherent to recommendations. I } \\
\text { can't say there is a shared decision process going } \\
\text { on. It's kind of like the radiologist is deciding; I'm } \\
\text { respecting the radiologist; they're respecting the } \\
\text { radiologist. } \\
\text { I try to lay out what the options are and explain the } \\
\text { pros and cons [of] the different options, and I try } \\
\text { to keep it in layman's terms... Most people are able } \\
\text { to give me an idea of which direction. They're like, } \\
\text { "Oh, I would worry too much and I just want to } \\
\text { have it [removed]," or "I really just don't want to } \\
\text { have any surgery." People are usually pretty clear } \\
\text { on what they want... I usually say, "My preference } \\
\text { would be this, but they're both possible options." } 33\end{array}$ \\
\hline
\end{tabular}

$\mathrm{PCP}=$ primary care provider.

according to the Mayo ${ }^{20}$ model was $7.1 \%$ [interquartile range, $4.6 \%-10.3 \%]$ ), who were surveyed up to 3 years after the nodule was detected, 50\% reported at least mild distress (measured with the Impact of Event Scale), with $24 \%$ experiencing moderate or severe levels. ${ }^{19}$ In Dr Slatore's longitudinal study of patients with an average nodule size of $6 \mathrm{~mm}$ (average risk of lung cancer, $10 \%[\mathrm{SD}, 12 \%]$ ) who were surveyed, on average, 4 months following detection, 39\% reported distress, $16 \%$ at moderate or severe levels. ${ }^{21}$ Although the average levels of distress decreased over time, almost $60 \%$ reported having mild or greater levels of distress at least once during surveillance, and $25 \%$ still had at least mild distress after 2 years of nodule surveillance. ${ }^{22}$ Notably, the average distress scores in both our studies were higher than those reported among lung cancer screening trial ${ }^{23,24}$ participants with nodules, although they followed the same trend of a short-term peak in distress that tended to decline over time. ${ }^{25,26}$

We also evaluated adherence to recommendations regarding nodule surveillance, including the separate contributions of patients and clinicians in the chain of adherence. We found in our longitudinal nodule study that patients and clinicians were each adherent approximately $75 \%$ of the time, and almost $40 \%$ of participants had at least one episode of nonadherence during surveillance, ${ }^{27}$ echoing the results of other studies. ${ }^{28-30}$ Importantly, clinician nonadherence was not associated with lung cancer risk factors, suggesting that when clinicians deviate from surveillance guidelines, they make this decision based on factors extrinsic to the patient's objective risk of lung cancer, a result found in other studies. ${ }^{29,31}$ However, despite reporting in qualitative studies that clinicians sometimes deviate from guidelines (eg, order an earlier scan) based on a patient's distress (Table 2), ${ }^{32,33}$ there was no association between distress and clinician adherence. This finding suggests that clinicians underestimate distress or do not guide management decisions based on it. Furthermore, some clinicians believed there was an "optimal" level of distress that might motivate patients to be more adherent to recommended surveillance and that completely alleviating distress might have the 
unintended consequence of reducing adherence. ${ }^{32}$ In actuality, however, patients who were distressed were less adherent to surveillance, and there was no level of distress that was associated with improved adherence. This finding is similar to results in other cancer screening settings, ${ }^{34}$ in which distress surrounding a false-positive result is negatively associated with adherence to subsequent screening. By contrast, highquality patient-clinician communication (as rated by patients) was associated with increased patient adherence to recommended nodule surveillance.

These results quantified the occurrence and magnitude of the problems, but we wanted to evaluate how communication strategies might mitigate them. In general, participants were satisfied with communication with their clinicians overall, and many reported it to be of high quality. However, we also found some systemic problems. Focusing first on the information exchange domain in our qualitative studies, we learned that participants had very little information about their nodules, a sentiment voiced by virtually every participant in our studies. Indeed, we titled our first papers, "What do you mean, a spot?"17 and "What the heck is a nodule?" 18 because those were the exact words so many used when describing their experiences. The participants implicitly understood that the nodule was related to lung cancer, but very few had an accurate understanding of the level of risk, the plans for surveillance, or the rationale for active surveillance rather than biopsy (Table 2).

These findings were confirmed in our quantitative studies, ${ }^{19,21}$ in which most participants dramatically overestimated their risk of lung cancer. For example, in the longitudinal study, the mean \pm SD lung cancer risk was $10 \% \pm 12 \%,{ }^{20}$ whereas the average perceived risk was $39 \% \pm 26 \%$. Cancer risk was $<30 \%$ for $95 \%$ of participants, but only $30 \%$ perceived that the risk was $<30 \%$. Participants also knew very little about the natural history of pulmonary nodules, ${ }^{19}$ and their knowledge did not improve over the course of surveillance. ${ }^{22,35}$ The large majority of participants reported that they did not receive or could not remember receiving information about their risk of cancer. ${ }^{19}$

Because patient self-report only reflects one-half of the communication dyad, we also interviewed primary care providers (PCPs) and pulmonologists to learn their approach to communication with patients with pulmonary nodules. PCPs confirmed that they seldom directly provided information about the risk of lung cancer (Table 2) and other details about surveillance to their patients. ${ }^{32}$ They offered several explanations, including lack of time, lack of confidence in their own estimate of cancer risk, and the concern that providing too many details would be overwhelming and might actually increase patient distress. Pulmonologists, who mostly described seeing patients with larger nodules, more often provided risk information, although not universally. ${ }^{33}$ Thus, we are confident that most patients with small nodules receive little information about their nodule, and the information they do receive is seldom tailored to their individual cancer risk.

Interestingly, and contrary to our hypotheses, selfperceived risk of lung cancer, as a measure of adequate information exchange, was not consistently associated with distress. Although distress was common, it was not nearly as frequent as patients' near universal lack of knowledge about cancer risk. Despite their limited knowledge of cancer risk, many patients were satisfied with the care and information they had received and did not seem distressed. This dichotomy seemed to be explained by the patients' trust in their clinicians, which was related to how clinicians communicated in the patient as person domain (Table 2). As one participant said, "She's a good doctor, because she would call me back if it was serious. She wouldn't just let me go."18

We also evaluated the association between information exchange and distress quantitatively. Perceived risk was not associated with distress in the large cross-sectional study or at baseline in the longitudinal study. However, perceived risk was modestly associated with distress in the longitudinal analyses, even though distress levels decreased during the period of active surveillance while perceived risk remained stable (a trend confirmed by the qualitative analyses). Overall, these findings suggest that strategies designed to improve knowledge about small nodules, with a goal to align the actual and perceived risk of lung cancer, may be insufficient to mitigate distress.

We next evaluated the association between the patient as person domain and distress. The qualitative studies suggested that patients experienced less distress when their clinicians were empathic and generated trust (Table 2). ${ }^{17,18,26}$ The quantitative studies strongly confirmed this finding. In the longitudinal study, we evaluated specific aspects of the patient as person domain and found that communication strategies which included partnership with the clinician, a personal relationship with the clinician, whether the clinician provided a positive and a clear approach to the problem, and whether 
the clinician was interested in the participant's life were all associated with decreased distress. ${ }^{22}$

Turning to shared decision-making, we asked if participants wanted to make decisions by themselves about nodule surveillance, whether they wanted their clinician to decide for them, or whether they wanted to share the decision. In the quantitative studies, using the Control Preferences Scale (CPS), ${ }^{36}$ participants almost always had a preferred role for the surveillance decision (56\% shared, $24 \%$ clinician-controlled, and $20 \%$ patientcontrolled) but in almost $40 \%$ of encounters, they could not describe their actual role. ${ }^{37}$ Although most patients wanted to participate in decision-making, ${ }^{19,37}$ patients infrequently engaged in decision-making with clinicians, ${ }^{38}$ often not recognizing that a decision had even been made. This finding was corroborated by clinicians who also reported that they seldom provided the level of information about the nodule that would be required to engage in true shared decision-making. In an international survey of clinicians who care for patients with pulmonary nodules, one-half reported that they are open to shared decision-making with patients about nodule evaluation. ${ }^{39}$ In qualitative interviews, however, PCPs and many pulmonologists reported that they rarely engaged in shared decision-making with their patients about nodule evaluation (Table 2). ${ }^{32,33}$ Based on these findings and the fact that information exchange about nodules was often inadequate, we suspect that true shared decision-making about nodule surveillance options seldom occurs, despite guidelines for pulmonary nodule evaluation explicitly recommending shared decision-making. ${ }^{7}$

Among those participants able to rate their role in decision-making, a shared process was not associated with satisfaction with or perceived quality of medical care, lung cancer risk, reported quality of information received, or distress. ${ }^{2,37}$ However, role concordance in decision-making (ie, having the same preferred and actual decision-making roles) was associated with satisfaction with and perceived quality of medical care, although not with knowledge or distress. Similarly, the inability to report how the decision was made was not associated with distress (G. C. S., unpublished data).

Finally, the therapeutic alliance domain of communication was qualitatively evaluated. Not surprisingly, given the inadequate knowledge about nodules, patients often did not know the plan for surveillance (Table 2). ${ }^{17-19,35}$ This lack of therapeutic alliance may explain some of the failure of distress to diminish over time among some patients. Most patients did not understand that surveillance is typically limited to 2 years (depending on nodule size) or that radiographic stability over that interval usually confirms that the nodule is benign. ${ }^{17,19,26}$ Without that understanding, some patients experienced persistently elevated levels of distress throughout the period of radiographic surveillance and even after surveillance had ended. ${ }^{22,26}$ Meanwhile, the lack of therapeutic alliance and consequent poor understanding of the evaluation plan may also explain our finding that patients often were nonadherent to the surveillance plan. Without a robust nodule-tracking system in place, some patients would have failed to receive any surveillance at all. ${ }^{27}$ Unfortunately, systems to prevent patients from "falling through the cracks" during nodule evaluation are not available in many health-care settings, ${ }^{40}$ despite being recognized as a critical need by clinicians. ${ }^{32}$

\section{Summary and Recommendations}

These studies confirmed our hypotheses that for patients with incidentally detected nodules, distress is common, sometimes severe, and often long-lasting. A parallel finding is that nonadherence to recommended surveillance is frequent, with multiple causes. In general, patients were satisfied with the communication with their clinicians in the patient as person domain and often reported high levels of trust. However, there were clear deficiencies in patients' knowledge about nodules and a lack of shared decisionmaking. Despite these communication deficiencies, their impact on distress and adherence may be low. Indeed, it seems that communication strategies focusing on the patient as person domain are more likely to have an effect on patient-centered outcomes.

Clinicians were worried that too much distress was obviously detrimental to patients. They used multiple strategies to decrease distress but one that stood out was some clinicians' decision to avoid talking about cancer. Patients uniformly asked for more information about nodules, specifically about the risk of cancer, and those who did receive it more often found this information reassuring rather than anxiety-provoking. ${ }^{19}$ Accordingly, the strategy of withholding cancer information to reduce distress is likely ineffectual. Clinicians also believed that no distress might be associated with worse adherence. Our results echo those from mammography, ${ }^{34}$ which also found that distress is associated with worse adherence with no "optimal" level. Thus, we believe that the risk of unintended consequences from interventions designed to increase knowledge about the risk of lung cancer and/or decrease distress is low. 
Patient as person

Recognize that identifying a pulmonary nodule is often distressful although frequently underreported

Discuss the nodule directly with the patient and provide a written summary

Examples

- Schedule an office or telephone visit to discuss the nodule

- A written summary should:

- Provide information about the nodule and address common concerns

- Avoid medical jargon or sending the CT report without further explanation

- See e-Appendix 1 for an example of a patient-centered notification letter

Actively elicit patient feelings

Examples

- "It's common to be distressed after learning you have a pulmonary nodule; how are you feeling?"

- "What's on your mind?"

- "Some people with a nodule worry they have lung cancer... what have you been thinking?"

Provide reassurance and resources to decrease distress

Make it easy for patients with persistent concerns to contact a knowledgeable clinician

Examples

- Provide telephone number for nurse coordinator/manager

- Clarify ability to message clinician through the electronic health record

Recognize that the nodule may be an important concern for patients and allow time for discussion of the patient's questions. Avoid minimizing or dismissive language

Information exchange

Patient-level suggestions

Provide information about the causes of nodules, rationale for active surveillance rather than immediate biopsy, and follow-up plan details, including benefits and harms

Report the semi-quantitative risk of lung cancer and relevant nodule information that relates to risk prediction (eg, lack of growth decreases malignancy risk)

Describe the follow-up plan in detail, including possible steps if the nodules change (eg, biopsy or surgery for growing nodule)

Use pictures, summary tables, and plain, simple language

Provide list of signs and symptoms that should prompt contact

Outline key imaging dates and subsequent office visits or telephone calls and provide a copy

Provide written and/or online educational resources for obtaining further information

Examples

- Nodule risk calculator: http://reference.medscape.com/calculator/solitary-pulmonary-nodule-risk

- Nodule patient education: http://www.thoracic.org/patients/patient-resources/resources/lung-nodules-online.pdf

Provide smoking cessation guidance if applicable, framed as a "teachable moment"

System-level suggestions

Health-care systems can develop system-wide tools to increase patients' knowledge and understanding of the lung cancer evaluation process

Health-care systems should develop tools to monitor and ensure adherence to follow-up recommendations

Shared decision-making

Clarify that active surveillance is a decision that the patient can discuss and question

Example

- "Let's talk together about what to do about your nodule"

Ask what role the patient prefers in the decision-making process

Example

- "When we make this decision about what to do about your nodule, some patients want to make the decision on their own, some just want me to decide, and many want something in the middle. How about you?"

If the patient is comfortable with a shared approach, actively engage patients in decisions regarding the follow-up evaluation

(Continued) 
Take the patient's values and preferences into account before making a final decision

Examples

- "Some people are worried about getting lung cancer when thinking about nodule follow-up; what do you think?"

- "I know you have worried about radiation exposure in the past, so let's talk about that before we decide on a plan."

- "Most of the time, the right decision is to watch the nodule over time, when we get another CT scan. But some people want to have an answer right away. How do you feel about waiting?"

- "How would you like to get the results of your next CT scan?"

Therapeutic alliance

Ask patients what they expect at the outset of the encounter to help define roles and prevent assumptions

Evaluate patients' understanding of the concepts presented

Examples

- “To make sure I didn't forget to tell you anything, can you repeat back to me when you're going to get your next CT scan? And what are you going to do if you have more questions or start to feel distressed?"

The link between actual risk of lung cancer, perceived risk, and distress is both interesting and complicated. We hypothesized that a large driver of distress for patients with nodules would be a misperception that the risk of lung cancer was much higher than the actual risk. Although we found that indeed this misperception was common, it does not seem to be strongly associated with distress.

Interventions that focus on information about nodules, one of the primary goals of decision aids, may be necessary to improve knowledge but are likely not sufficient to improve distress if used on their own without communication strategies that also include communication about individual patient's values and preferences.

Despite widespread recommendations for shared decision-making, we were not surprised that it rarely occurred, as in many other clinical contexts. ${ }^{41}$ Even among participants who could rate how the nodule surveillance decision was made, shared decision-making and role concordance were not associated with distress. We measured shared decision-making with the CPS, a widely used but imperfect instrument. ${ }^{42,43}$ Our findings on the whole indicate that "true" shared decision-making, with adequate information exchange and consideration of patients' preferences and values, seldom occurred. The CPS does not capture these subtleties, and we therefore suggest not using the CPS as a single measure of successful shared decision-making. It may be adequate to use in preliminary studies of new communication interventions, such as decision aids, as a measure of communication processes but may not be appropriate as a measure of actual patient-centered outcomes.

\section{Patient and Clinician Suggestions}

Table 3 includes several examples of suggestions that participants offered for how clinicians could improve communication. Overall, patients wanted more information about the relative size of the nodule, the associated risk of lung cancer, and the plan for follow-up (e-Appendix 1 includes a sample information letter). Additional strategies that patients found reassuring but were underutilized by clinicians included explaining that nodules were a common finding and highlighting the small size of the nodule on the CT image. ${ }^{19} \mathrm{We}$ also included several examples of how to improve communication in the patient as person domain. Changes in this domain may be challenging but likely essential for improving patient-centered outcomes. Meanwhile, clinicians expressed a need for better tools to share information with patients and systems-level methods to improve adherence to their recommended surveillance. To meet some of these needs, we developed a patient education document about pulmonary nodules. ${ }^{44}$

\section{Limitations}

As with all studies, the present studies have limitations. First, the longitudinal analyses and mixed-methods analyses improve the likelihood that the associations observed are causal, but observational studies can never truly assess causality. Thus, communication interventions should be empirically tested for their effect on patient-centered outcomes. Second, because two diverse cohorts were studied, the overall results may be more generalizable than the results would be if taken separately. However, there is still a need to study associations of communication with patient-centered outcomes in other settings, most notably among patients undergoing lung cancer screening. Third, our studies assessed communication as reported by patients and clinicians, which may differ from actual communication. Only recorded or observed studies of clinic visits or telephone conversations can assess what really happened. 


\section{Conclusions}

Many patients are diagnosed with a pulmonary nodule, and it is common to be distressed, sometimes severely, as a result. Patients want more information and should be provided with it. It is unclear, however, if improved information exchange, by itself and without attention to individual patient values and preferences, will improve patient-centered outcomes. Similarly, shared decisionmaking is important, but additional or new measures are needed because current instruments are mostly associated with process measures that may be less relevant for patients. Furthermore, decision aids, which mainly focus on knowledge, may not suffice for improving other patient-centered outcomes such as distress. $^{45}$

Although we focused on patients with incidentally detected nodules, these results from routine clinical practice may be more generalizable to patients with screening-detected nodules in the real world than results from randomized trials. ${ }^{46}$ If so, screening is likely to cause distress for many patients, and current recommendations to use decision aids may be insufficient to mitigate that distress. We are currently conducting a study to assess the impact of screening and quality of communication on patient-centered outcomes in the usual-care context. ${ }^{47}$ Given the large number of patients who may undergo screening in the near future, it is important to continue to study and refine strategies to minimize its harm.

\section{Acknowledgments}

Financial/nonfinancial disclosures: None declared.

Role of sponsors: The sponsor had no role in the design of the study, the collection and analysis of the data, or the preparation of the manuscript.

Other contributions: We are indebted to many people and organizations. First, we thank VA's Health Services Research and Development Service and the National Cancer Institute for sponsoring our studies and career development. We thank our research coordinators, including Terri Kneeland, MPH, Emilie Zoltick, MPH, ScD, Denise Clarke, MBA, Ashley Wagner, MS, and especially Sara Golden, MPH, for doing the lion's share of the work on these studies. We thank all our mentors for teaching us how to do research and fostering our careers. In particular, we thank David Au, $\mathrm{MD}$, and Michael Gould, MD, for introducing us and showing us that collaboration is way more fun and fruitful than competition. Finally, and most importantly, we thank the study participants. We started and continue this work because of these patients, for the ultimate goal of using our research to make their lives better. The views expressed in this article are those of the authors and do not necessarily represent the views of the Department of Veterans Affairs or the US Government. The Department of Veterans Affairs did not have a role in the conduct of the study; in the collection, management, analysis, or interpretation of data; or in the preparation of the manuscript.

Additional information: The e-Appendix can be found in the Supplemental Materials section of the online article.

\section{References}

1. Gould MK, Tang T, Liu IL, et al. Recent trends in the identification of incidental pulmonary nodules. Am J Respir Crit Care Med. 2015;192(10):1208-1214.

2. Ost D, Fein AM, Feinsilver SH. Clinical practice. The solitary pulmonary nodule. N Eng J Med. 2003;348(25):2535-2542.

3. Humphrey LL, Deffebach M, Pappas M, et al. Screening for lung cancer with low-dose computed tomography: a systematic review to update the US Preventive Services Task Force recommendation. Ann Intern Med. 2013;159(9):411-420.

4. Holden WE, Lewinsohn DM, Osborne ML, et al. Use of a clinical pathway to manage unsuspected radiographic findings. Chest. 2004;125(5):1753-1760.

5. Aberle DR, Adams AM, Berg CD, et al. Reduced lung-cancer mortality with low-dose computed tomographic screening. $N$ Engl J Med. 2011;365(5):395-409.

6. MacMahon H, Austin JH, Gamsu G, et al. Guidelines for management of small pulmonary nodules detected on CT scans: a statement from the Fleischner Society. Radiology. 2005;237(2): 395-400.

7. Gould MK, Donington J, Lynch WR, et al. Evaluation of individuals with pulmonary nodules: when is it lung cancer?: Diagnosis and management of lung cancer, 3rd ed: American College of Chest Physicians Evidence-Based Clinical Practice Guidelines. Chest. 2013;143(5 Suppl):e93S-e120S.

8. Harris RP, Sheridan SL, Lewis CL, et al. The harms of screening: a proposed taxonomy and application to lung cancer screening. JAMA Intern Med. 2013;174(2):281-285.

9. Brewer NT, Salz T, Lillie SE. Systematic review: the long-term effects of false-positive mammograms. Ann Intern Med. 2007;146(7): 502-510.

10. Nelson HD, Pappas M, Cantor A, Griffin J, Daeges M, Humphrey L. Harms of breast cancer screening: systematic review to update the 2009 US Preventive Services Task Force Recommendation Harms of Breast Cancer Screening. Ann Intern Med. 2016;164(4):256-267.

11. Street RL Jr, Makoul G, Arora NK, Epstein RM. How does communication heal? Pathways linking clinician-patient communication to health outcomes. Patient Educ Couns. 2009;74(3) 295-301.

12. Epstein RM, Street RL Jr. Patient-Centered Communication in Cancer Care: Promoting Healing and Reducing Suffering. NIH Publication No. 07-6225. Bethesda, MD: National Cancer Institute; 2007.

13. Slatore C, Horeweg N, Jett J, et al. An official American Thoracic Society Research Statement: a research framework for pulmonary nodule evaluation and management. Am J Respir Crit Care Med. 2015;192(4):500-514.

14. Wiener RS, Gould MK, Arenberg DA, et al. An official American Thoracic Society/American College of Chest Physicians Policy Statement: implementation of low-dose computed tomography lung cancer screening programs in clinical practice. Am J Respir Crit Care Med. 2015;192(7):881-891.

15. Mead N, Bower P. Patient-centredness: a conceptual framework and review of the empirical literature. Soc Sci Med. 2000;51(7):1087-1110.

16. de Haes $\mathrm{H}$, Bensing $\mathrm{J}$. Endpoints in medical communication research, proposing a framework of functions and outcomes. Patient Educ Couns. 2009;74(3):287-294.

17. Wiener RS, Gould MK, Woloshin S, Schwartz LM, Clark JA. "What do you mean, a spot?": a qualitative analysis of patients' reactions to discussions with their doctors about pulmonary nodules. Chest. 2013;143(3):672-677.

18. Slatore CG, Press N, Au DH, Curtis JR, Wiener RS, Ganzini L. What the heck is a "nodule"? A qualitative study of veterans with pulmonary nodules. Ann Am Thorac Soc. 2013;10(4):330-335.

19. Freiman MR, Clark JA, Slatore CG, et al. Patients knowledge, beliefs, and distress associated with detection and evaluation of incidental pulmonary nodules: results from a multi-center survey. J Thorac Oncol. 2016;11(5):700-708. 
20. Swensen SJ, Silverstein MD, Ilstrup DM, Schleck CD, Edell ES. The probability of malignancy in solitary pulmonary nodules. Application to small radiologically indeterminate nodules. Arch Intern Med. 1997;157(8):849-855.

21. Slatore CG, Golden SE, Ganzini L, Wiener RS, Au DH. Distress and patient-centered communication among veterans with incidental (not screen-detected) pulmonary nodules. A cohort study. Ann Am Thorac Soc. 2015;12(2):184-192.

22. Slatore CG, Wiener RS, Golden SE, Au DH, Ganzini L. Longitudinal assessment of distress among veterans with incidental pulmonary nodules. Ann Am Thorac Soc. 2016;13(11):1983-1991.

23. Slatore CG, Sullivan DR, Pappas M, Humphrey LL. Patient-centered outcomes among lung cancer screening recipients with computed tomography: a systematic review. J Thorac Oncol. 2014;9(7):927-934.

24. Brain K, Lifford KJ, Carter B, et al. Long-term psychosocial outcomes of low-dose CT screening: results of the UK Lung Cancer Screening randomised controlled trial. Thorax. 2016;71(11):996-1005.

25. van den Bergh KA, Essink-Bot ML, Borsboom GJ, Scholten ET, van Klaveren RJ, de Koning HJ. Long-term effects of lung cancer computed tomography screening on health-related quality of life: the NELSON trial. Eur Respir J. 2011;38(1):154-161.

26. Wiener RS, Gould MK, Woloshin S, Schwartz LM, Clark JA. 'The thing is not knowing': patients' perspectives on surveillance of an indeterminate pulmonary nodule. Health Expect. 2015;18(3):355-365.

27. Moseson EM, Wiener RS, Golden SE, et al. Patient and clinician characteristics associated with adherence. A cohort study of veterans with incidental pulmonary nodules. Ann Am Thorac Soc. 2016;13(5): 651-659.

28. Wiener RS, Gould MK, Slatore CG, Fincke BG, Schwartz LM, Woloshin S. Resource use and guideline concordance in evaluation of pulmonary nodules for cancer: too much and too little care. JAMA Intern Med. 2014;174(6):871-880.

29. Tanner NT, Porter A, Gould M, Li XJ, Vachani A, Silvestri GA. Physician assessment of pre-test probability of malignancy and adherence with guidelines for pulmonary nodule evaluation. Chest. 2017;152(2):263-270.

30. Singh H, Hirani K, Kadiyala H, et al. Characteristics and predictors of missed opportunities in lung cancer diagnosis: an electronic health record-based study. J Clin Oncol. 2010;28(20):3307-3315.

31. Tanner NT, Aggarwal J, Gould MK, et al. Management of pulmonary nodules by community pulmonologists: a multicenter observational study. Chest. 2015;148(6):1405-1414.

32. Golden SE, Wiener RS, Sullivan D, Ganzini L, Slatore C. Primary care providers and a system problem: a qualitative study of clinicians caring for patients with incidental pulmonary nodules. Chest. 2015;148(6):1422-1429.

33. Wiener RS, Slatore CG, Gillespie C, Clark JA. Pulmonologists' reported use of guidelines and shared decision-making in evaluation of pulmonary nodules: a qualitative study. Chest. 2015;148(6): $1415-1421$.
34. O’Donnell S, Goldstein B, DiMatteo MR, Fox SA, John CR, Obrzut JE. Adherence to mammography and colorectal cancer screening in women 50-80 years of age: the role of psychological distress. Womens Health Issues. 2010;20(5):343-349.

35. Sullivan DR, Golden SE, Ganzini L, Hansen L, Slatore CG. 'I still don't know diddly': a longitudinal qualitative study of patients' knowledge and distress while undergoing evaluation of incidental pulmonary nodules. NPJ Prim Care Respir Med. 2015;25:15028.

36. Degner LF, Sloan JA, Venkatesh P. The Control Preferences Scale. Can J Nurs Res. 1997;29(3):21-43.

37. Sullivan DR, Golden SE, Ganzini L, Wiener RS, Eden KB, Slatore CG. Association of decision-making with patients' perceptions of care and knowledge during longitudinal pulmonary nodule surveillance. Ann Am Thorac Soc. 2017;14(11): $1690-1696$.

38. Slatore CG, Au DH, Press N, Wiener RS, Golden SE, Ganzini L. Decision making among veterans with incidental pulmonary nodules: a qualitative analysis. Respir Med. 2015;109(4):532-539.

39. Iaccarino JM, Simmons J, Gould MK, et al. Clinical equipoise and shared decision-making in pulmonary nodule management. Ann Am Thorac Soc. 2017;14(6):968-975.

40. Simmons J, Gould MK, Iaccarino J, Slatore CG, Wiener RS. Systemslevel resources for pulmonary nodule evaluation in the United States: a national survey. Am J Respir Crit Care Med. 2016;193(9): 1063-1065.

41. Zikmund-Fisher BJ, Couper MP, Singer E, et al. Deficits and variations in patients' experience with making 9 common medical decisions: the DECISIONS survey. Med Decis Making. 2010;30(suppl 5):85S-95S.

42. Scholl I, Loon MK, Sepucha K, et al. Measurement of shared decision making - a review of instruments. Zeitschrift für Evidenz, Fortbildung und Qualität im Gesundheitswesen. 2011;105(4): 313-324.

43. Department of Health and Human Services. Part 1. Overview Information-6 2 2016. Developing Measures of Shared Decision Making (RO1). Available at: https://grants.nih.gov/grants/guide/pafiles/PA-16-424.html. Accessed June 30, 2017.

44. American Thoracic Society. Patients. Available at: http://www. thoracic.org/patients/. Accessed July 6, 2017.

45. Stacey D, Legare F, Lewis KB. Patient decision aids to engage adults in treatment or screening decisions. JAMA. 2017;318(7):657-658.

46. Wiener RS, Koppelman E, Slatore CG, Clark JA. Patients' impressions of communication with their clinicians surrounding low-dose CT lung cancer screening: a qualitative study. Am J Respir Crit Care Med. 2015;191:A6120.

47. Miranda LS, Datta S, Melzer AC, et al. Rationale and design of the lung cancer screening implementation. Evaluation of PatientCentered Care Study. Ann Am Thorac Soc. 2017;14(10):1581-1590. 